\title{
Efeito do miriadenolídeo isolado de Alomia myriadenia (Asteraceae) sobre o tumor de Erlich ascítico no camundongo
}

[Effect of myriadenolide isolated from Alomia myriadenia (Asteraceae) on Ehrlich tumor in its ascitic form]

\author{
D. Verçosa Júnior ${ }^{1}$, E.M. Souza-Fagundes ${ }^{2}$, G.D. Cassali ${ }^{3}$, E.L. Ribeiro ${ }^{1}$, \\ C.L. Zani ${ }^{2}$ e M.M. Melo ${ }^{1 *}$
}

${ }^{1}$ Escola de Veterinária - UFMG

Caixa Postal 567

30123-970 - Belo Horizonte, MG

${ }^{2}$ Centro de Pesquisas René Rachou - FIOCRUZ, Belo Horizonte, MG

${ }^{3}$ Instituto de Ciências Biológicas - UFMG, Belo Horizonte, MG

\begin{abstract}
RESUMO
Estudou-se atividade antineoplásica de um produto natural isolado de Alomia myriadenia (miriadenolídeo) no modelo do tumor de Ehrlich em camundongos. Dezoito fêmeas de camundongo Swiss foram inoculadas com $2 \times 10^{7}$ células viáveis de tumor de Ehrlich via intraperitoneal $(0,3 \mathrm{ml})$ e posteriormente distribuídas aleatoriamente em três grupos que receberam: grupo I (controle) - 0,3ml de solução de Hanks; grupo II $31 \mu \mathrm{g} / \mathrm{kg}$ de miriadenolídeo; e grupo III - $139 \mu \mathrm{g} / \mathrm{kg}$ de miriadenolídeo. No oitavo dia de experimento, foram realizados exames hematológicos e perfil protéico sérico eletroforético. Coletou-se todo o líquido ascítico para avaliação do volume, aparência, $\mathrm{pH}$, contagem de células viáveis e inviáveis, realização de esfregaços para contagem de células claras e escuras, leucócitos e avaliação das regiões organizadoras de nucléolos argentafins (AgNORs). Foram realizados exames macro e microscópicos do baço, fígado e rins e aspirado o conteúdo da medula óssea dos fêmures direito e esquerdo de cada animal para avaliação da relação mielóide:eritróide. Não houve diferença significativa no volume, $\mathrm{pH}$, contagem de células viáveis e inviáveis entre os três grupos estudados, observando-se valores de $17,6 \times 10^{4}$ células tumorais viáveis no grupo III, $27,7 \times 10^{4}$ no grupo II e $21,1 \times 10^{4}$ no grupo I. As AgNORs apresentaram-se pequenas, com distribuição difusa e incontáveis no grupo I, e em menor quantidade no grupo III. Os animais do grupo III apresentaram a menor concentração protéica total sérica $(4,7 \mathrm{~g} / \mathrm{dl})(\mathrm{P} \leq 0,05)$ quando comparados com os do grupo II $(5,3 \mathrm{~g} / \mathrm{dl})$ e do grupo $\mathrm{I}(5,1 \mathrm{~g} / \mathrm{dl})$. Os valores de albumina foram semelhantes nos três grupos $(2,6 \mathrm{~g} / \mathrm{dl})$, e as globulinas totais foram maiores $(\mathrm{P} \leq 0,05)$ no grupo II $(2,71 \mathrm{~g} / \mathrm{dl})$ quando comparadas com os valores médios do grupo III $(2,11 \mathrm{~g} / \mathrm{dl})$ e semelhantes ao grupo I $(2,43 \mathrm{~g} / \mathrm{dl})$. Não houve diferença entre alfa e beta globulinas entre os três grupos estudados, porém as gamaglobulinas foram maiores $(\mathrm{P} \leq 0,05)$ no grupo II $(1,72 \mathrm{~g} / \mathrm{dl})$ quando comparadas com as do grupo III $(1,13 \mathrm{~g} / \mathrm{dl})$. Com relação ao eritrograma e leucograma, não houve diferença significativa entre os grupos tratados. A relação mielóide:eritróide foi maior $(\mathrm{P} \leq 0,05)$ no grupo III $(1,40)$ quando comparada com a relação nos grupos I $(0,92)$ e II $(0,61)$. A contagem de reticulócitos também foi maior $(\mathrm{P} \leq 0,05)(11,2)$ no grupo III, quando comparada com as dos grupos I $(4,3)$ e II $(3,6)$. Em todos os grupos, observou-se degeneração hepática.
\end{abstract}

Palavras-chave: miriadenolídeo, tumor de Ehrlich, hematologia, eletroforese, alterações microscópicas, camundongos

Recebido em 15 de dezembro de 2005

Aceito em 13 setembro de 2006

*Autor para correspondência (corresponding author)

E-mail: marilia@vet.ufmg.br

Apoio: FAPEMIG/CNPq 


\begin{abstract}
Antitumoral activity of a natural product of Alomia myriadenia (myriadenolide) in Ehrlich tumor in mice was studied. Eighteen Swiss female mice were intra-peritoneal inoculated $2 \times 10^{7}$ viable cells of Ehrlich Tumor $(0.3 \mathrm{ml})$ and randomly distributed in three groups receiving via intra-peritoneal on the $3^{\text {rd }}$ and $5^{\text {th }}$ day post-inoculation the following treatments: group I (control) - 0.3ml Hanks solution; group II: $31 \mu \mathrm{g} / \mathrm{kg}$ myriadenolide; and group III: $139 \mu \mathrm{g} / \mathrm{kg}$ myriadenolide. On the eighth day of the experiment blood profile and protein serum electrophoresis were performed. All ascitic liquid was collected to evaluate the volume and $\mathrm{pH}$; to observe the aspect; to count viable and no viable cells, dark and clear cells, leukocytes and nucleolar organizer regions (NORs). Macro and microscopic exams were performed and bone marrow was aspirated from right and left femurs of each animal to evaluate myeloid:erythroid ratio. It was not observed difference in volume, $\mathrm{pH}$, counts viable and no viable cells in the groups,

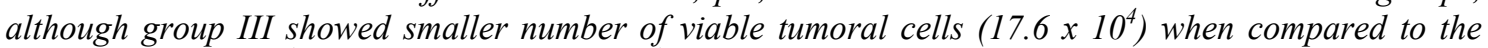
group II $\left(27.7 \times 10^{4}\right)$ and group I $\left(21.1 \times 10^{4}\right)$. The investigation of NORs to evaluate the proliferative capacity of tumoral cells after myriadenolide treatment showed that cells were smaller, uncountable and with diffuse distribution in group I. They were in lower quantity in group III. These results suggest that myriadenolide in dose $139 \mu \mathrm{g} / \mathrm{kg}$ (group III) delay the tumoral growing and, probably, cell proliferation. The animals of group III showed lower value of total protein $(4.7 \mathrm{~g} / \mathrm{dl})(P \leq 0.05)$ when compared to animals from group II $(5.3 \mathrm{~g} / \mathrm{dl})$ and group I $(5.1 \mathrm{~g} / \mathrm{dl})$. The values of albumin were similar in all groups $(2.6 \mathrm{~g} / \mathrm{dl})$ and total globulin was higher $(P \leq 0.05)$ in group II $(2.71 \mathrm{~g} / \mathrm{dl})$ when compared to mean values of group III $(2.11 \mathrm{~g} / \mathrm{dl})$ and similar to group I $(2.43 \mathrm{~g} / \mathrm{dl})$. The decrease of total protein in group III occurred by globulin reduction. There was no difference in alpha and beta globulin in the three studied groups, although the immunoglobulins were higher $(P \leq 0.05)$ in group II $(1.72 \mathrm{~g} / \mathrm{dl})$ when compared to group III $(1.13 \mathrm{~g} / \mathrm{dl})$. These results suggest the viable number of tumoral cells in group II could cause the increase response of $\operatorname{IgM}$ reflecting on the final value of immunoglobulins. In relation to erythrogram and leukogram there was no statistical difference. The myeloid:erythroid ratio was higher $(P \leq 0.05)$ in group III (1.40) when compared to groups I (0.92) and II (0.61). Reticulocytes count were higher $(P \leq 0.05)$ (11.2) in group III, when compared to groups I (4.3) and II (3.6). In all groups, hepatic degeneration was observed.
\end{abstract}

Keywords: myriadenolide, Ehrlich Tumor, blood profile, electrophoresis, microscopic alterations, mice

\section{INTRODUÇ̃̃O}

Em um estudo prévio, foi relatada a atividade imunossupressora in vitro do miriadenolídeo (12S.16-dihydroxy-ent-ladda-7.13-dien-15,16olide) um diterpeno tipo labdano isolado da Alomia myriadenia Schultz-Bip. ex. Baker (Asteraceae) (Zani et al., 2000). Esse produto natural inibiu a proliferação de linfócitos estimulados por fitohemaglutinina (PHA), induzindo apoptose em monócitos, sem alterar a viabilidade ou funcionalidade de células T CD4+ e CD8+ in vitro (Souza-Fagundes et al., 2003a). O mecanismo de ativação da via apoptótica foi investigado em células Jurkat e THP-1, sendo demonstrado que este composto induzia morte nestas células por ativação da via mitocondrial (Souza-Fagundes et al., 2003b). Embora os resultados in vitro sejam muito interessantes, ainda não foram relatados estudos sobre o potencial imunossupressor e antitumoral deste diterpeno em modelos experimentais in vivo.

O objetivo deste estudo foi relatar os resultados do efeito in vivo do miriadenolídeo no modelo experimental de camundongos com tumor de Ehrlich ascítico (TEA).

\section{MATERIAL E MÉTODOS}

Dezoito fêmeas de camundongo Swiss albino, não isogênicas, com oito semanas de idade, e peso entre 25 e $30 \mathrm{~g}$, foram divididas em três grupos com seis animais em cada um, alojadas em gaiolas $(40 \times 45 \times 25 \mathrm{~cm})$, onde recebiam água e ração ad libitum e submetidas ao controle artificial de ciclos de luminosidade (12 horas de luz/12 horas de escuro). Os animais foram submetidos a um período de 10 dias de adaptação antes do início do experimento. 
A circunferência abdominal foi usada para inferir o desenvolvimento do tumor ascítico, tendo sido medida imediatamente antes da inoculação das células tumorais, e diariamente durante o experimento. Em paralelo, determinava-se o peso dos animais, bem como o consumo hídrico e de ração.

O TEA foi mantido em camundongos Swiss por transplantes seriados. Após os testes de viabilidade e contagem celular, as células tumorais em suspensão foram preparadas numa solução salina $(0,84 \%)$ com uma concentração final de $2 \times 10^{7}$ células viáveis/animal $(0,3 \mathrm{ml})$, inoculadas por via intraperitoneal (IP) em todos os camundongos, segundo protocolo proposto por Guerra (1983).

O miriadenolídeo, um produto natural isolado da A. myriadenia (Zani, et al., 2000), foi dissolvido em DMSO $(10 \mathrm{mg} / \mathrm{ml})$ e diluído com salina fisiológica (solução de Hanks) para as concentrações finais de 2,5 e $10 \mu \mathrm{g} / \mathrm{ml}$. Essas soluções foram administradas pela via IP.

Os camundongos foram inoculados com as células tumorais e distribuídos aleatoriamente em três grupos submetidos aos seguintes tratamentos no $3^{\circ}$ e $5^{\circ}$ dias pós-inoculação: grupo I administração de $0,3 \mathrm{ml}$ de solução de Hanks (controle); grupo II - administração de $31 \mu \mathrm{g} / \mathrm{kg}$ do miriadenolídeo; e grupo III - administração de $139 \mu \mathrm{g} / \mathrm{kg}$ do miriadenolídeo.

Células isoladas do tumor de Ehrlich foram cultivadas in vitro em presença de diferentes concentrações do miriadenolídeo por 18 horas. A proliferação e viabilidade celular foram determinadas pelo ensaio de MTT realizados em três experimentos independentes. Portanto, as doses utilizadas acima foram escolhidas com base no valor da $\mathrm{IC}_{50}$ in vitro para células neoplásicas do tumor de Ehrlich $(3,5 \mu \mathrm{g} / \mathrm{ml})$ e na disponibilidade de miriadenolídeo puro (Fig. 1).

No oitavo dia de experimento, após anestesia dos animais com solução de $50 \mathrm{mg} / \mathrm{kg}$ de xilazina e $50 \mathrm{mg} / \mathrm{kg}$ de quetamina por via intramuscular, coletou-se $0,3 \mathrm{ml}$ de sangue de todos os animais, no espaço retroorbital, com auxilio de tubo de microhematócrito segundo técnica descrita por Anderson (1998). As amostras foram acondicionadas em tubos plásticos contendo $0,005 \mathrm{ml}$ de solução de ácido etilenodiamino tetra acético $(\text { EDTA })^{1}$ a $10 \%$, para realização de exames hematológicos (eritrograma, contagem total de leucócitos e plaquetas) em aparelho de contagem eletrônica veterinário (ABX'S-VET) ${ }^{2}$, confecção de esfregaços sangüíneos fixados em solução May-Grunwald ${ }^{3}$ e corados em solução Giemsa ${ }^{3}$ para contagem diferencial de leucócitos segundo Ferreira Neto et al. (1978).

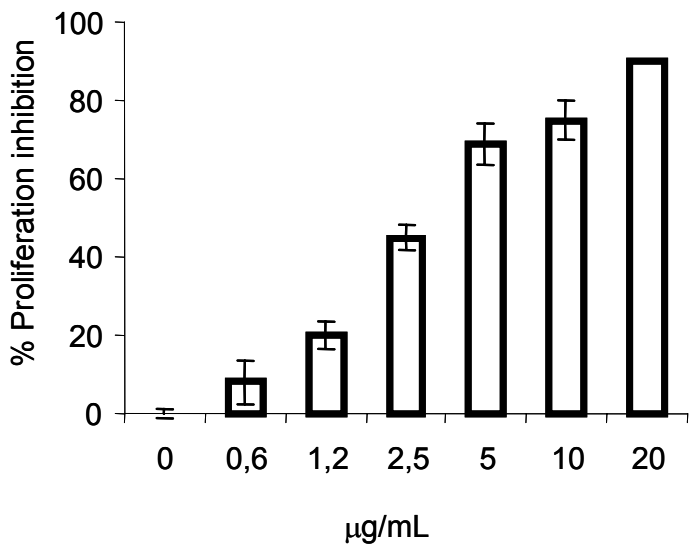

Figura 1. Porcentagem de inibição na proliferação de células do tumor de Ehrlich após diferentes concentrações de miriadenolídeo.

Juntamente com a coleta de sangue para as avaliações hematológicas, foi coletado cerca de $1,0 \mathrm{ml}$ de sangue de cada animal, acondicionado em tubos plásticos sem anticoagulante e centrifugado a $3.000 \mathrm{rpm}$ durante cinco minutos. O soro obtido foi armazenado a $-20^{\circ} \mathrm{C}$, sendo utilizado para dosagens de proteína total sérica por refratometria e perfil eletroforético em fitas de celulose, segundo técnica descrita por Naoum (1990) modificada (45 minutos de corrida em cuba de fonte para eletroforese ${ }^{4}$ ), e lidas em densitômetro $^{5}$ com comprimento de onda de $520 \mathrm{~nm}$.

Após a coleta sangüínea, foi realizada eutanásia por deslocamento cervical; incisão da linha Alba e então coletado todo o líquido ascítico, sendo avaliados volume, aparência, $\mathrm{pH}$, contagem de células viáveis e inviáveis na câmara de

${ }^{1}$ Reagen - Quimibrás Indústrias Quimicas S.A - Rio de Janeiro, Brasil.

${ }^{2}$ ABX Diagnóstics - EUA

${ }^{3}$ Doles Reagentes e Equipamentos para Laboratórios Ltda Goiânia, Brasil.

${ }^{4}$ Techow Instrumentos Científicos Ltda. (ARGOS 12) - São Paulo,Brasil.

${ }^{5}$ CELM - Indústria Brasileira (DS53), Brasil. 
Neubauer (Guerra, 1983). Foram realizados dois esfregaços do líquido ascítico de cada animal, sendo que uma das lâminas foi fixada com MayGruenwald $^{3}$ e corada por meio Giemsa ${ }^{3}$ (MGG) para contagem de células claras e escuras (Silva, 2003) e leucócitos, e a segunda lâmina foi fixada com álcool metílico e corada pela prata, para avaliação das regiões organizadoras de nucléolos (AgNORs) em microscópio óptico, com objetiva de imersão (Alves et al., 1999). Após essa contagem, calculou-se a porcentagem e a relação de células escuras e claras e o número médio de AgNORs por lâmina.

Após a coleta do líquido ascítico, foram retirados o baço e o fígado de todos os animais e pesados em balança eletrônica ${ }^{6}$, com precisão de cinco decimais. Foram procedidos os cálculos de valores relativos dos órgãos coletados (peso do órgão/peso do animal), para minimizar os efeitos das diferenças de pesos entre animais. Amostras de baço, fígado e rins foram seccionados e fixados em formol neutro tamponado a $10 \%$ e incluídos em parafina histológica ${ }^{7}$. Os blocos de parafina foram seccionados em micrótomo, sendo obtidos cortes de $4 \mu \mathrm{m}$, para posterior desparafinização em xilol, hidratação em concentrações decrescentes de álcool etílico, colorações com soluções de hematoxilina ${ }^{8}$ e $\operatorname{eosina}^{8}$, nova desidratação em concentrações crescentes de álcoois, e montagem das lâminas.

Durante a necropsia, foram retirados os fêmures direito e esquerdo de cada animal, seccionadas as partes craniais destes ossos com um corte em bisel, inserida uma agulha de hipodérmica embebida em $\operatorname{EDTA}^{1}$ a $3 \%$, e aspirado o conteúdo da medula óssea para realização de esfregaço. As lâminas foram fixadas em MayGrunwald $^{3}$ e posteriormente coradas por meio Giemsa $^{3}$, segundo técnica descrita por Kohayagawa (2003) $)^{9}$ em comunicação pessoal, e procedidas avaliações quantitativas dos valores de células mielóides e eritróides em microscópio óptico, com ocular de 10x, e objetiva de imersão de $100 x$.

Com o objetivo de verificar o metabolismo das células neoplásicas, foi realizada coloração dos esfregaços do líquido ascítico, utilizando-se

\footnotetext{
${ }^{6}$ Bioprecisa (FA2104N), Brasil.

${ }^{7}$ Labsynth Ltda - Diadema, Brasil.

${ }^{8}$ Merck - Darmstadt, Alemanha.

${ }^{9}$ Kohayagawa, 2003 - FMVZ-UNESP - Botucatu, SP.
}

mistura de solução aquosa de nitrato de $\operatorname{prata}^{8}$ a $50 \%$, com solução de ácido fórmico ${ }^{1}$ a $1 \%$, e gelatina microbiológica incolor. Depois de hidratadas, as lâminas foram incubadas em câmara úmida e escura, em estufa a $40^{\circ} \mathrm{C}$, por 33 minutos e, em seguida, lavadas em água deionizada, desidratadas com concentrações crescentes de álcoois (Ploton et al., 1986).

Da mesma forma, com o uso de microscopia óptica, com ocular de $10 x$ e objetiva $100 x$, nas lâminas de líquido ascítico coradas pela prata, foram procedidas as caracterizações morfológica e a contagem de NORs, que, segundo Ploton et al. (1986), podem ser consideradas como unidades ativas de regiões organizadoras de nucléolos. Foram contadas as NORs presentes em 30 núcleos de células neoplásicas escolhidas aleatoriamente, incluindo-se na contagem somente as que se encontravam individualizadas com pontos pretos ou marrons, com o objetivo de obter-se uma avaliação qualitativa do potencial proliferativo das células, e possíveis diferenças destes.

Foram realizadas análises estatísticas simples, ANOVA - Dunkan, com nível de significância de $5 \%$ para as variáveis avaliadas, segundo Sampaio (1998).

\section{RESULTADOS E DISCUSSÃO}

Apesar de o grupo III ter apresentado ganho de peso final de $5,38 \mathrm{~g}$ e os grupos II e I de $3,67 \mathrm{~g}$ e $4,75 \mathrm{~g}$ respectivamente, não houve diferença estatística entre os três grupos experimentais (Tab. 1).

Não houve diferença significativa na circunferência abdominal entre os três grupos estudados (Tab. 2). Porém no grupo III, no quinto, sexto e sétimo dias, não houve alteração da circunferência abdominal, permanecendo com os mesmos valores médios. Diferentemente no grupo II, houve aumento até o sétimo dia, possivelmente em decorrência da menor dose do miriadenolídeo $(31 \mu \mathrm{g} / \mathrm{kg})$. Contudo, no oitavo dia, ocorreu uma inversão na resposta clínica, pois o grupo III mostrou um rápido aumento da circunferência abdominal. 
Tabela 1. Peso nos dias 0 ( $\mathrm{PO}=$ um dia antes do experimento) e 8 ( $\mathrm{P} 8=$ antes da eutanásia), ganho de peso final (GP) e peso relativo do fígado ( $\mathrm{PrF}$ ) e baço (PrB) dos camundongos com tumor de Ehrlich ascítico, tratados com solução de Hanks (grupo I - controle) e miriadenolídeo (grupo II - $31 \mu \mathrm{g} / \mathrm{kg}$ e grupo III $139 \mu \mathrm{g} / \mathrm{kg})$

\begin{tabular}{lccc} 
Pesos $(\mathrm{g})$ & Grupo I & Grupo II & Grupo III \\
\hline PO & $23,93 \pm 1,52$ & $24,05 \pm 1,44$ & $23,12 \pm 2,26$ \\
P8 & $28,68 \pm 1,81$ & $27,7166 \pm 2,95$ & $28,48 \pm 4,12$ \\
GP & $4,75 \pm 2,58 \mathrm{a}$ & $3,67 \pm 2,78$ & $5,37 \pm 2,55$ \\
PrF & $0,056 \pm 0,010$ & $0,056 \pm 0,020$ & $0,062 \pm 0,003$ \\
PrB & $0,0046 \pm 0,0013$ & $0,0110 \pm 0,0136$ & $0,0055 \pm 0,0017$ \\
\hline
\end{tabular}

Não houve diferença entre os grupos $(\mathrm{P}>0,05)$.

Tabela 2. Circunferência abdominal (CircA) dos camundongos com tumor de Ehrlich ascítico, tratados com solução de Hanks (grupo I - controle) e miriadenolídeo (grupo II - $31 \mu \mathrm{g} / \mathrm{kg}$ e grupo III - $139 \mu \mathrm{g} / \mathrm{kg}$ ), durante o experimento

\begin{tabular}{lccc}
\hline CircA (dm) & Grupo I & Grupo II & Grupo III \\
\hline Primeiro dia & $84,8 \pm 3,1$ & $84,0 \pm 3,0$ & $82,8 \pm 3,1$ \\
Segundo dia & $88,7 \pm 4,3$ & $89,7 \pm 4,3$ & $87,0 \pm 3,3$ \\
Terceiro dia & $87,8 \pm 2,6$ & $88,2 \pm 4,0$ & $86,5 \pm 3,4$ \\
Quarto dia & $88,0 \pm 3,2$ & $88,2 \pm 3,5$ & $88,2 \pm 1,5$ \\
Quinto dia & $91,8 \pm 4,3$ & $92,5 \pm 4,3$ & $91,7 \pm 4,7$ \\
Sexto dia & $92,7 \pm 4,6$ & $95,0 \pm 6,1$ & $91,8 \pm 4,8$ \\
Sétimo dia & $94,2 \pm 6,8$ & $96,3 \pm 6,4$ & $91,7 \pm 9,5$ \\
Oitavo dia & $99,2 \pm 6,8$ & $96,7 \pm 3,6$ & $98,3 \pm 9,1$ \\
\hline
\end{tabular}

Não houve diferença entre os grupos $(\mathrm{P}>0,05)$.

Apesar de ter sido coletado $1,2 \mathrm{ml}$ de líquido ascítico no grupo II, $2,6 \mathrm{ml}$ no grupo I e $3,1 \mathrm{ml}$ no grupo III, não se verificou diferença estatística entre os três grupos estudados (Tab.3). No grupo II, observou-se uma correlação positiva, $90,8 \%$, entre volume de líquido ascítico e circunferência abdominal, ou seja, menor volume de líquido ascítico e menor volume abdominal. Todos os animais de todos os grupos apresentaram líquido ascítico de aspecto fibrinoso e hemorrágico. A produção do líquido ascítico no tumor de Ehrlich é creditada principalmente à hiperpermeabilidade dos capilares presentes na cavidade peritoneal (Senger et al., 1983). Essa alteração vascular deveu-se à ação das células neoplásicas induzindo aumento da expressão de receptores para o fator de motilidade autócrina (FMA), ao mesmo tempo em que secretam grande quantidade desse fator. A ligação do FMA ao seu receptor induz angiogênese e aumenta a permeabilidade vascular por alterar a morfologia das células endoteliais, com subseqüente formação de grande quantidade de líquido ascítico. Matsuzaki et al. (2003) relataram que camundongos inoculados com tumor de Ehrlich ascítico e tratados com Pfaffia paniculata (ginseng brasileiro) durante 10 dias por gavagem, mostraram diminuição do volume do líquido ascítico, além de apresentarem menor número de células tumorais, e atribuíram a diminuição do líquido a um possível efeito antiinflamatório do ginseng.

A análise dos esfregaços do líquido ascítico mostrou que em todos os grupos havia predomínio de células escuras, arredondadas com citoplasma moderado, basofílico, com poucos vacúolos com bordas definidas e núcleos hipercromáticos, ovais em sua maioria. No grupo II, ocorreu o maior percentual $(82,7 \%)$ de células escuras contadas em 10 campos (Tab. 3) e o menor percentual de células claras (17,3\%). No grupo III, verificou-se menor porcentagem de células escuras $(60,5 \%)$ e o maior percentual de células claras (39,5\%). Com base nestes resultados, sugere-se que o miriadenolídeo, na dose de $31 \mu \mathrm{g} / \mathrm{kg}$ (grupo II), favoreceu a presença de células escuras, culminando com a menor produção de líquido ascítico. Na dose de $139 \mu \mathrm{g} / \mathrm{kg}$ (grupo III), o fármaco favoreceu a presença de células claras, culminando com a maior produção de líquido ascítico. Os vacúolos citoplasmáticos das células claras sugerem algum tipo de atividade secretora de acordo com Silva (2003), que classificou as células do TEA em claras e escuras pela sua morfologia. A razão de células escuras/claras/campo foi de 4,9 no grupo II, 2,4 no grupo I e 2,3 no grupo III. 
Tabela 3. Volume e pH do líquido ascítico (LA), número de células tumorais (CT) viáveis (CTv) e inviáveis $(\mathrm{CTi})$, número e valor relativo $(\mathrm{VR})$ de células claras $(\mathrm{Cc})$ e escuras $(\mathrm{Ce})$ de camundongos com tumor de Ehrlich ascítico, tratados com solução de Hanks (grupo I - controle) e miriadenolídeo (grupo II $-31 \mu \mathrm{g} / \mathrm{kg}$ e grupo III $-139 \mu \mathrm{g} / \mathrm{kg}$ )

\begin{tabular}{|c|c|c|c|}
\hline & Grupo I & Grupo II & Grupo III \\
\hline $\mathrm{LA}(\mathrm{ml})$ & $2,6 \pm 2,7$ & $1,21 \pm 1,1$ & $3,1 \pm 3,3$ \\
\hline $\mathrm{pH}(\mathrm{LA})$ & $7,83 \pm 0,52$ & $7,67 \pm 0,52$ & $7,67 \pm 0,41$ \\
\hline $\mathrm{CTV}^{1}(\mathrm{ml} / \mathrm{LA})$ & $21.100 \pm 17.724$ & $27.675 \pm 23.085$ & $17.608 \pm 14.041$ \\
\hline $\mathrm{CTi}^{1}(\mathrm{ml} / \mathrm{LA})$ & $866,7 \pm 1880,9$ & $466,7 \pm 444,6$ & $300,0 \pm 304,9$ \\
\hline $\mathrm{CT}^{2}(\mathrm{MGG})$ & $23,1 \pm 13,9$ & $48,4 \pm 38,4$ & $20,3 \pm 13,2$ \\
\hline $\mathrm{Ce}^{2}$ & $17,1 \pm 13,3$ & $42,3 \pm 39,3$ & $14,6 \pm 12,8$ \\
\hline $\mathrm{Cc}^{2}$ & $6,05 \pm 7,32$ & $6,02 \pm 1,59$ & $5,68 \pm 4,37$ \\
\hline $\operatorname{VRC} \mathrm{Ce}^{2}(\%)$ & $70,13 \pm 23,50$ & $82,68 \pm 8,36$ & $60,48 \pm 35,07$ \\
\hline VR $\mathrm{Cc}^{2}(\%)$ & $29,87 \pm 23,50$ & $17,32 \pm 8,36$ & $39,52 \pm 35,07$ \\
\hline $\mathrm{Ce} / \mathrm{Cc}$ & $2,4 \pm 2,5$ & $4,9 \pm 10,8$ & $2,3 \pm 1,8$ \\
\hline Leucócitos $^{2}$ & $0,23 \pm 0,29$ & $3,40 \pm 6,08$ & $0,33 \pm 0,37$ \\
\hline $\begin{array}{l}\text { Leucócitos/ } \\
\text { Total de células }\end{array}$ & $0,008 \pm 0,008 b$ & $0,0443 \pm 0,041 \mathrm{a}$ & $0,017 \pm 0,015$ \\
\hline
\end{tabular}

${ }^{1}$ Células tumorais por ml de líquido ascítico x $10^{4}$.

${ }^{2}$ Células em esfregaço de líquido ascítico - média de 10 campos.

Não houve diferença entre os grupos $(P>0,05)$ exceto na relação leucócitos/total de células em que letras diferentes significam diferença $(\mathrm{p} \leq 0,05)$.

Não houve diferença no número de células tumorais viáveis (Tab. 3) entre os grupos, observando-se $27,7 \times 10^{4}$ no grupo II, $21,1 \times 10^{4}$ no grupo I e $17,6 \times 10^{4}$ no grupo III. Portanto, no grupo com menor produção de líquido ascítico (grupo II) ocorreu maior número de células tumorais viáveis e no de maior produção de líquido ascítico (grupo III), menor número. Matsuzaki et al. (2005), ao tentarem elucidar o mecanismo pelo qual o resíduo butanólico de $P$. paniculata aumentava a sobrevivência de camundongos, realizaram um experimento no qual os animais eram tratados por sete dias com esse produto, mas não encontraram diferenças estatísticas em relação ao volume de fluido ascítico e o número de células tumorais entre o grupo de animais tratados e o grupo controle. Portanto, os resultados desta pesquisa são semelhantes aos resultados de Matsuzaki et al. (2005). O menor número de células tumorais viáveis, observado no grupo III tratado com a maior concentração do miriadenolídeo, sugere que o miriadenolídeo na dose de $139 \mu \mathrm{g} / \mathrm{kg}$ possui uma possível ação antineoplásica.

A investigação das AgNORs, para avaliar a capacidade proliferativa das células do tumor frente ao tratamento pelo miriadenolídeo, mostrou que elas se apresentavam pequenas, com distribuição difusa e incontáveis no grupo I, e em menor quantidade no grupo III. Independente do grupo, as AgNORs estavam fortemente unidas, constituindo estruturas argirofílicas grandes, arredondadas ou irregulares, preenchendo totalmente o nucléolo e, em alguns casos, pequenas AgNORs podiam ser vistas dispersas pelo núcleo, sugerindo elevado potencial proliferativo dessas células (Derenzini, 2000).

Vários autores utilizam a determinação das AgNORs como uma estratégia indicadora da proliferação celular (Silva et al., 2004; Silva et al., 2006; Romão-Correa et al., 2005). Segundo Silva et al. (2004), a freqüência de AgNORs no núcleo tem sido significativamente maior em células neoplásicas malignas do que em células normais, reativas. Romão-Correa et al. (2005) utilizaram as AgNORs como um método de prognóstico complementar a outros procedimentos histológicos, vinculando o seu número e disposição em células de câncer de pele humano, demonstrando que estas variam em relação à disposição, ao número e à forma, estando associadas com os níveis de transcrição de rDNA e multiplicação celular. Diante do exposto por Romão-Correa et al. (2005), pode-se sugerir que o miriadenolídeo na dose de $139 \mu \mathrm{g} / \mathrm{kg}$ (grupo III) retarda o crescimento tumoral e, provavelmente, a proliferação celular in vivo, semelhante às observações de Souza- 
Fagundes et al. (2003b), quanto à atividade citotóxica desse diterpeno in vitro. Os autores demonstraram que o miriadenolídeo apresentava atividade pró-apoptótica para células Jurkat e THP-1, sugerindo o seu potencial antitumoral, como um possível candidato para o desenvolvimento de novos agentes úteis no tratamento de malignidades hematológicas.

Relatos prévios do potencial imunossupressor do miriadenolídeo in vitro (Souza-Fagundes et al., 2003a) foram motivos de investigação do impacto desse produto natural sobre a resposta imune celular e humoral. A toxicidade de agentes antitumorais pode levar à supressão da hematopoiese, que inclui todos os elementos do sangue como leucócitos, plaquetas e células vermelhas (Ghosh et al., 1999). A mielossupressão é a principal e também a mais freqüente complicação na quimioterapia do câncer (Mazumder et al., 2005). O número médio de leucócitos (cel/ml) no líquido ascítico (Tab.3) foi de 0,2 no grupo I; 3,4 no grupo II e 0,3 no grupo III, sem diferença estatística entre os grupos $(\mathrm{P}>0,05)$. Sabe-se que a resposta inflamatória nessa forma de tumor é discreta, caracterizada por mínima infiltração de macrófagos e por influxo tardio de células polimorfonucleares para a cavidade (Fecchio et al., 1990). Porém, a razão entre leucócitos e células tumorais no líquido ascítico foi maior nos grupos II $(0,044)$ e III $(0,017)$ quando comparados com o valor de 0,008 no grupo I, sugerindo que na dose de $31 \mu \mathrm{g} / \mathrm{ml}$ o miriadenolídeo produziu maior quimiotaxia de leucócitos.

Os animais do grupo III apresentaram a menor concentração protéica total sérica $(4,7 \mathrm{~g} / \mathrm{dl})$, $(\mathrm{P} \leq 0,05)$ quando comparados com os grupos II $(5, \overline{3} \mathrm{~g} / \mathrm{dl})$ e $\mathrm{I}(5,1 \mathrm{~g} / \mathrm{dl})$ (Tab. 4). Os valores de albumina foram semelhantes nos três grupos $(2,6 \mathrm{~g} / \mathrm{dl})$, e as globulinas totais foram maiores $(\mathrm{P} \leq 0,05)$ no grupo II $(2,71 \mathrm{~g} / \mathrm{dl})$ quando comparadas com os valores médios do grupo III $(2,11 \mathrm{~g} / \mathrm{dl})$ e semelhantes aos do grupo I $(2,43 \mathrm{~g} / \mathrm{dl})$. A redução do valor da proteína total no grupo III deveu-se à redução das globulinas. Não houve diferença entre alfa e beta globulinas nos três grupos estudados, já as gamaglobulinas foram maiores $(\mathrm{P} \leq 0,05)$ no grupo II $(1,72 \mathrm{~g} / \mathrm{dl})$ quando comparadas com o grupo III $(1,13 \mathrm{~g} / \mathrm{dl})$. Estes resultados sugerem que um número maior de células tumorais viáveis no grupo II poderia produzir maior resposta de $\operatorname{IgM}$ ou de $\operatorname{IgA}$ refletindo sobre $\mathrm{o}$ valor final das gamaglobulinas. Ghosh e Saha (2000) verificaram correlação entre o nível de $\operatorname{IgA}$ plasmática em camundongos com tumor de Ehrlich e o crescimento tumoral, sugerindo que a modulação do crescimento tumoral por IgA é também mediada por seu efeito em fatores imunocelulares antitumoral do hospedeiro.

Tabela 4. Proteinograma sérico de camundongos com tumor de Ehrlich ascítico, tratados com solução de Hanks (grupo I - controle) e miriadenolídeo (grupo II - $31 \mu \mathrm{g} / \mathrm{kg}$ e grupo III - $139 \mu \mathrm{g} / \mathrm{kg}$ )

\begin{tabular}{lccc}
\hline & Grupo I & Grupo II & Grupo III \\
\hline Proteína total $^{1}$ & $5,1 \pm 0,63 \mathrm{a}$ & $5,3 \pm 0,53 \mathrm{a}$ & $4,7 \pm 0,21 \mathrm{~b}$ \\
Albumina $^{1}$ & $2,67 \pm 0,36 \mathrm{a}$ & $2,63 \pm 0,23 \mathrm{a}$ & $2,56 \pm 0,04 \mathrm{a}$ \\
Globulina total $^{1}$ & $2,43 \pm 0,34 \mathrm{ab}$ & $2,71 \pm 0,63 \mathrm{a}$ & $2,11 \pm 0,19 \mathrm{~b}$ \\
Albumina/globulina $^{1}$ & $1,108 \pm 0,144 \mathrm{a}$ & $1,027 \pm 0,292 \mathrm{a}$ & $1,218 \pm 0,107 \mathrm{a}$ \\
$\alpha$ e $\beta$ globulinas $^{1}$ & $0,879 \pm 0,156 \mathrm{a}$ & $1,038 \pm 0,191 \mathrm{a}$ & $0,986 \pm 0,099 \mathrm{a}$ \\
$\gamma$ globulina $^{1}$ & $1,551 \pm 0,267 \mathrm{ab}$ & $1,645 \pm 0,627 \mathrm{a}$ & $1,126 \pm 0,136 \mathrm{~b}$ \\
\hline
\end{tabular}

${ }^{1}$ Eletroforese

Letras diferentes significam diferença estatística $(\mathrm{p} \leq 0,05)$.

A relação mielóide:eritróide foi maior $(\mathrm{P} \leq 0,05)$ no grupo III $(1,40)$ do que nos grupos I $(0,92)$ e II $(0,61)$ (Tab. 5). Entretanto, observa-se que o grupo II apresentou a relação abaixo dos limites considerados normais para a espécie $(0,8$ a 2,4$)$, indicando que a produção de eritrócitos excedeu a granulopoiese. Isso foi comprovado pelos resultados hematológicos (Tab. 5) demonstrados pelos valores dos eritrócitos. A medula óssea detém uma população heterogênea de células e vários progenitores hematopoiéticos cuja proliferação e diferenciação são controladas por fatores comuns (Wood et al., 1998). Ela não só corresponde a um reservatório de células primordiais, como também proporciona um microambiente exclusivo, onde ocorrem 
proliferação e diferenciação ordenada de células precursoras do sangue. No grupo III, percebe-se aumento da granulopoiese, pois essa relação ultrapassa 1 (Jain, 1993) indicando que a granulopoiese está excedendo a eritropoiese, e o miriadenolídeo na dose de $139 \mu \mathrm{g} / \mathrm{kg}$ poderia estimular células precursoras da linhagem mielóide.

Tabela 5. Exames hematológicos e relação Mielóide:Eritróide de camundongos com tumor de Ehrlich ascítico, tratados com solução de Hanks (grupo I - controle) e miriadenolídeo (grupo II - $31 \mu \mathrm{g} / \mathrm{kg}$ e grupo III $-139 \mu \mathrm{g} / \mathrm{kg})$

\begin{tabular}{lccc}
\hline & Grupo I & Grupo II & Grupo III \\
\hline Hemácias $(\mu \mathrm{l})$ & $6.815 .000 \pm 1.945 .567 \mathrm{a}$ & $7.970 .000 \pm 735.037 \mathrm{a}$ & $7.560 .000 \pm 617.252 \mathrm{a}$ \\
Hemoglobina $(\mathrm{g} / \mathrm{dl})$ & $12,42 \pm 3,64 \mathrm{a}$ & $14,23 \pm 1,42 \mathrm{a}$ & $13,63 \pm 0,69 \mathrm{a}$ \\
Hematócrito $(\%)$ & $34,8 \pm 10,1 \mathrm{a}$ & $40,1 \pm \mathrm{a}$ & $39,2 \pm 2,5 \mathrm{a}$ \\
VCM $(\mathrm{fl})$ & $51,0 \pm 1,3 \mathrm{a}$ & $50,3 \pm 1,5 \mathrm{a}$ & $52,0 \pm 1,2 \mathrm{a}$ \\
HCM $(\mathrm{pg})$ & $18,1 \pm 0,5 \mathrm{a}$ & $17,9 \pm 0,5 \mathrm{a}$ & $18,1 \pm 0,8 \mathrm{a}$ \\
CHCM $(\mathrm{g} / \mathrm{dl})$ & $35,6 \pm 0,7 \mathrm{a}$ & $35,5 \pm 0,6 \mathrm{a}$ & $34,8 \pm 0,9 \mathrm{a}$ \\
Leucócitos $(\mu \mathrm{l}))$ & $7116,7 \pm 3.973,6 \mathrm{a}$ & $6716,7 \pm 1838,9 \mathrm{a}$ & $6433,3 \pm 1858,7 \mathrm{a}$ \\
Neutrófilos $(\mu \mathrm{l})$ & $3111,8 \pm 2.761,9 \mathrm{a}$ & $1811,0 \pm 1007,8 \mathrm{a}$ & $2221,1 \pm 1149,4 \mathrm{a}$ \\
Linfócitos $(\mu \mathrm{l})$ & $3.411,3 \pm 1425,1 \mathrm{a}$ & $4.334,0 \pm 1128,5 \mathrm{a}$ & $3428,0 \pm 1204,1 \mathrm{a}$ \\
Monócitos $(\mu \mathrm{l}))$ & $47,2 \pm 61,8 \mathrm{a}$ & $38,3 \pm 50,9 \mathrm{a}$ & $133,7 \pm 209,4 \mathrm{a}$ \\
Ring cels $(\mu \mathrm{l})$ & $512,3 \pm 417,9 \mathrm{a}$ & $1451,3 \pm 2325,0 \mathrm{a}$ & $553,0 \pm 364,1 \mathrm{a}$ \\
Plaquetas $(\mu \mathrm{l})$ & $666.333,3 \pm 79.561 \mathrm{a}$ & $692.333,3 \pm 80.505 \mathrm{a}$ & $622.166,7 \pm 70.576 \mathrm{a}$ \\
Reticulócitos $(\mu \mathrm{l})$ & $4,3 \pm 0,78 \mathrm{~b}$ & $3,6 \pm 1,32 \mathrm{~b}$ & $11,2 \pm 5,35 \mathrm{a}$ \\
Mieloide/eritroide & $0,92 \pm 0,11 \mathrm{~b}$ & $0,61 \pm 0,21 \mathrm{~b}$ & $1,40 \pm 0,40 \mathrm{a}$ \\
\hline
\end{tabular}

Letras diferentes significam diferença estatística $(\mathrm{p} \leq 0,05)$

Apesar de os valores do eritrograma serem semelhantes (Tab. 5), no grupo I observou-se valor médio de eritrócitos abaixo do limite inferior considerado normal para a espécie de acordo com Moore (2000). Estes resultados podem estar associados ao reduzido período de vida do eritrócito, distúrbios no metabolismo e armazenamento do ferro e diminuição da saturação do ferro.

Não houve diferença estatística com relação aos valores hematimétricos (volume globular médio, hemoglobina globular média e concentração de hemoglobina globular média), nem com relação ao número de plaquetas entre os grupos estudados. A contagem de reticulócitos foi maior $(11,2)$ no grupo III, quando comparado com a dos grupos I $(4,3)$ e II $(3,6)$. Neste experimento, os animais do grupo III não apresentaram anemia, pois além de o número de eritrócitos estar normal também a concentração de hemoglobina e os índices hematimétricos estavam dentro dos limites de normalidade. Deve ser ressaltado que anemia normocítica normocrômica não regenerativa é um achado comum em pacientes com câncer.
Não houve diferença com relação ao número total de leucócitos (Tab. 5), que foram 7117/ $\mu$ l no grupo I, 6717/ $\mu$ l no grupo II e $6433 / \mu 1$ no grupo III. $\mathrm{O}$ número de leucócitos totais no grupo I deveu-se ao maior número de neutrófilos $(3112 / \mu 1)$. Estes resultados assemelham-se aos relatos de Segura et al. (1997) e Segura et al. (2000), os quais afirmaram que o desenvolvimento do tumor de Ehrlich ascítico é marcado por neutrofilia. Portanto, neste experimento nota-se que o miriadenolídeo foi capaz de reduzir até $41,8 \%$ do número absoluto de neutrófilos $(1811 / \mu 1$ no grupo II e $2221 / \mu 1$ no grupo III), demonstrando também seu potencial antiinflamatório, já que os neutrófilos se constituem uma das principais células envolvidas na resposta inflamatórias (Jain, 1993).

O mecanismo de elevação dos leucócitos e neutrófilos é obscuro no tumor de Ehrlich, contudo existem fortes indícios de que o fator estimulador de colônia (CSF) e o fator estimulador de colônia de granulócitos produzidos pelas células tumorais estejam envolvidos (Ogilvie, 1993, Morales et al., 1999). É importante reforçar que muitos tumores experimentais produzem mudanças marcantes na 
resposta hematopoiética medular e extramedular dos animais, causando anemia, depleção tímica, imunossupressão e leucocitose dependente de granulócitos (Bincoletto et al., 2005) confirmadas pelas observações desta pesquisa.

O grupo II apresentou o valor médio da contagem total de linfócitos de 4334/ $\mu 1$, sem diferença estatística quando comparado com os grupos III (3428/ $\mu \mathrm{l})$ e I $(3411 / \mu \mathrm{l})$ (Tab. 5), e alta correlação positiva $98,9 \%$ com número de células neoplásicas viáveis. O tumor de Ehrlich induz alterações significativas e precoces no sistema imune do hospedeiro, a partir da supressão da resposta celular (redução de linfócitos $\mathrm{T}$ helper-Th e da atividade das células NK) e indução da resposta humoral, sabidamente menos efetiva no combate do desenvolvimento tumoral (Segura et al., 1997; Morales et al., 1999; Segura et al., 2000; Pinto, 2003).

Neste experimento, o grupo I apresentou valores médios da contagem total de linfócitos de $3411 / \mu$ e o tratamento com o miriadenolídeo em menor concentração (grupo II) produziu aumento de $27,1 \%$ dessas células. Estes resultados confirmam os citados anteriormente: maiores valores de gamaglobulinas e peso do baço, ambos observados no grupo II. Deve ser ressaltado que a medula óssea é o principal local de hematopoese em animais sadios. A função primária da medula óssea é a produção de eritrócitos, granulócitos, monócitos e plaquetas. A produção de linfócitos na medula óssea é limitada, porque sua fonte principal é o baço e o tecido linfático periférico (Seybold et al., 1980). Portanto, o miriadenolídeo na dose de $31 \mu \mathrm{g} / \mathrm{kg}$ possivelmente é mielossupressor e estimulante da imunidade humoral.

A presença de neutrófilos heterófilos em forma de anel, comumente chamados de ring cells (Moore, 2000), é uma característica da espécie, e o maior número dessas células foi observado no grupo II $(1.451,3 / \mu \mathrm{l})$ quando comparado com o grupo III $(553 / \mu \mathrm{l})$ e o grupo I $(512,3 / \mu \mathrm{l})$, sugerindo que o miriadenolídeo em menor concentração provoca liberação de células imaturas na corrente sangüínea (Tab. 5). $\mathrm{O}$ grupo II apresentou valores de monócitos de $38,4 / \mu 1$, sem diferença estatística (Tab. 5) quando comparado com os grupos I $(47,2 / \mu \mathrm{l})$ e III $(133,7 / \mu \mathrm{l})$.
Independente da dose de miriadenolídeo utilizada foram observadas metástases no baço, fígado e rins com grande quantidade de células neoplásicas depositadas acima da cápsula desses órgãos (Tab. 6). Somente os grupos tratados com miriadenolídeo apresentaram ativação dos folículos linfóides no baço, confirmando os resultados anteriores da contagem absoluta de linfócitos.

O peso médio do fígado foi semelhante nos três grupos estudados e, apesar de o peso relativo do baço ter sido maior no grupo II $(0,0110 \mathrm{~g})$, foi estatisticamente semelhante aos dos grupos III $(0,0055 \mathrm{~g})$ e I $(0,0046 \mathrm{~g})$ (Tab. 1). Korekane (2003) e Verçosa Júnior (2005) também relataram aumento do peso relativo do baço em animais inoculados com tumor de Ehrlich e atribuíram este achado a uma maior ação hemocaterética (Cotran et al. 1996).

Em todos os grupos, observou-se degeneração hepática, inclusive no grupo-controle, assim não se pode atribuir a lesão ao miriadenolídeo e, possivelmente, ao tumor, pois Korekane et al. (2003) descreveram alteração nas células hepáticas com prejuízo das funções em camundongos com tumor de Ehrlich ascítico, causadas pelas citocinas (IL-1 e TNF $\alpha$ ), e Verçosa Júnior (2005) relatou degeneração turva dos hepatócitos em camundongos com tumor na forma sólida. Todavia, como no grupo III tratado com uma concentração maior de miriadenolídeo, cinco dos seis animais apresentaram hepatite supurada focal e congestão renal.

Os resultados deste estudo relatam pela primeira vez a atividade in vivo de um produto natural isolado de Alomia myriadenia no TEA em camundongos e permitem levantar algumas questões. Haveria dicotomia quanto ao impacto na resposta imune dos animais após tratamento com o miriadenolídeo? Uma ação estimulante da resposta humoral, supressora da resposta celular e mielossupressora? Em concentrações maiores esse composto apresentaria atividade antitumoral mais evidente? Para responder a essas questões, outras doses do miriadenolídeo e avaliação da dose letal $\left(\mathrm{DL}_{50}\right)$ e tempos de tratamento deverão ser estudados em futuros experimentos, considerando os relatos de Hazra et al. (2002), que estudaram o efeito do extrato da raiz da chicória (Cichorium intybus L.) contra o tumor de Ehrlich ascítico utilizando doses de 300, 500 e $700 \mathrm{mg} / \mathrm{kg} / \mathrm{dia}$ (por até 44dias). 
Efeito do miriadenolídeo isolado de Alomia myriadenia...

Tabela 6. Achados microscópicos do baço, fígado e rins de camundongos com tumor de Ehrlich ascítico, tratados com solução de Hanks (grupo I - controle) e miriadenolídeo (grupo II - $31 \mu \mathrm{g} / \mathrm{kg}$ e grupo III $139 \mu \mathrm{g} / \mathrm{kg})$

\begin{tabular}{|c|c|c|c|}
\hline Grupo & Tecido & Alterações microscópicas & $\begin{array}{l}\text { Animais } \\
\text { acometidos }\end{array}$ \\
\hline \multirow[t]{3}{*}{$\mathrm{I}$} & Baço & Discreta hiperplasia de folículos linfóides & $(2 / 6)$ \\
\hline & & Congestão esplênica intensa & $(2 / 6)$ \\
\hline & & Presença de células neoplásicas na serosa & $(4 / 6)$ \\
\hline \multirow[t]{3}{*}{$\mathrm{I}$} & Fígado & Esteatose hepática discreta & $(3 / 6)$ \\
\hline & & Hepatite mista multifocal discreta & $(3 / 6)$ \\
\hline & & Serosa com áreas de implantação do tumor & $(4 / 6)$ \\
\hline \multirow[t]{2}{*}{ I } & Rim & Nefrite intersticial discreta & $(1 / 6)$ \\
\hline & & Serosa com áreas de implantação do tumor & $(2 / 6)$ \\
\hline \multirow[t]{3}{*}{ II } & Baço & Folículos linfóides bastante reativos & $(4 / 6)$ \\
\hline & & Poucos megacariócitos & $(3 / 6)$ \\
\hline & & Presença de células neoplásicas na serosa & $(4 / 6)$ \\
\hline \multirow[t]{6}{*}{ II } & Fígado & Esteatose hepática multifocal & $(3 / 6)$ \\
\hline & & Presença de células leucocitárias peri-vascular e na & $(4 / 6)$ \\
\hline & & serosa & $(1 / 6)$ \\
\hline & & Presença de células gigantes & $(1 / 6)$ \\
\hline & & $\begin{array}{l}\text { Hepatócitos com citoplasma vacuolizado, às vezes } \\
\text { picnótico }\end{array}$ & $(4 / 6)$ \\
\hline & & Serosa com áreas de implantação do tumor & \\
\hline \multirow[t]{2}{*}{ II } & Rim & Congestão moderada no córtex e na medular & $(6 / 6)$ \\
\hline & & Serosa com áreas de implantação do tumor & $(1 / 6)$ \\
\hline \multirow[t]{3}{*}{ III } & Baço & Hiperplasia de folículos linfóides & $(5 / 6)$ \\
\hline & & Megacariócitos muito volumosos & $(1 / 6)$ \\
\hline & & Presença de células neoplásicas na serosa & $(4 / 6)$ \\
\hline \multirow[t]{3}{*}{ III } & Fígado & Esteatose hepática multifocal & $(5 / 6)$ \\
\hline & & Hepatite supurada focal & $(5 / 6)$ \\
\hline & & Serosa com áreas de implantação do tumor & $(3 / 6)$ \\
\hline \multirow[t]{2}{*}{ III } & Rim & Congestão moderada no córtex e na medular & $(5 / 6)$ \\
\hline & & Serosa com áreas de implantação do tumor & $(2 / 6)$ \\
\hline
\end{tabular}

\section{REFERÊNCIAS BIBLIOGRÁFICAS}

ALVES, V.A.; BACCHI, C.E.; VASSALO, J. Manual de Imuno-histoquimica. São Paulo: Sociedade Brasileira de Patologia, 1999, 270p.

ANDERSON, N.L. Criação e Medicina Básica dos Animais de Estimação "de Bolso". In: BIRCHARD, S.J.; SHERDING, R.G. Manual Saunders: Clínica de pequenos animais, Philadelphia: Saunders, 1998, cap.10, p.1523-1552.

BINCOLETTO C.; EBERLIN S.; CAMILA, A.V. et al. Effects produced by Royal Jelly on haematopoiesis: relation with host resistance against Ehrlich ascites tumour challenge. Internat. Immunopharm, v.5, p.679-688, 2005.

COTRAN R.S.; KUMAR, V.; ROBBINS, S.L. et al. Robins - Patologia Estrutural e Funcional. 5 ed. Rio de Janeiro: Guanabara Koogan S. A., 1996. 1277p.

DERENZINI, M. The AgNORs. Micron, v.31, p.117 - 120, 2000 .
FECCHIO, D.; SIROIS, P.; RUSSO, M. et al. Studies on inflammatory response induced by Ehrlich tumor in mice peritoneal cavity. Inflammation, v.14, p.125-132, 1990.

FERREIRA NETO, J.M.; VIANA, E.S.; MAGALHÃES, L.M. Patologia Clínica Veterinária. Belo Horizonte: Rabelo Brasil Ltda, 1978. 279p.

GHOSH, A.K.; SAHA S. Correlation and modulation of Ehrlich ascites tumor growth with tumor-plasma IgA. Indian J. Exp. Biol.,v.38, p.313-22, 2000.

GHOSH, M.; SADHU, U.; BHATTACHARYA, S. et al. Evaluation of toxicity of B-tethymustine, a new anticancer compound in mice. Cancer Lett., v.138, p.107-114, 1999.

GUERRA, J.L. Aspectos do processo inflamatório em camundongos portadores de Tumor de Ehrlich. 1983. 87p. Tese (Doutorado) - Faculdade de Medicina Veterinária e Zootecnia da USP, São Paulo, SP.

HAZRA, B.; SARKAR, R.; BHATTACHARYYA, S. et al. Tumour inhibitory of chicory root extract against Ehrlich 
ascites carcinoma in mice. Fitoterapia, v.73, p.730-733, 2002.

KOREKANE, H.; NISHIKAWA, A.; IMAMURA, K. Mechanisms mediating metabolic abnormalities in the livers of Ehrlich tumor-bearing mice. Arch. Bioch. Bioph., v.412, p.216-222, 2003

JAIN, N.C. Essentials of veterinary hematology. Philadelphia: Lea \& Febiger, 1993. 417p.

MATSUZAKI, P.; AKISUE, G.; OLORIS, S.C.S. et al. Effect of Pfaffia paniculata (Brasilian ginseng) on the Ehrlich tumor in its ascitic form. Life Sci., v.74, p.573-579, 2003

MATSUZAKI, P.; HARAGUCH, M.; AKSUE, G. et al. Antineoplastic effects of butanolic residue of Pfaffia paniculata. Cancer Lett., in press, 2005. Acesso Portal CAPES.

MAZUMDER, U.K.; GUPTA M.; KARKI, S.S. et al Syntesis and pharmacological activities of some monouclear Ru (II) complexes. Bioorganic \& Medicinal Chemistry, v.13, p.5766-5733, 2005 .

MORALES, J.R.; VÉLEZ, D.; SUBIZA, J.L. Ehrlich tumor stimulates extramedullar hematopoiesis in mice without secreting identifiable colony-stimulating factors and without engagement of host T cells. Exp. Hematol., v.27, p.17571767, 1999.

MOORE, D.M. Hematology of Rabbits. In: FELDMAN, B. F., ZINKL, J. G., JAIN, N. C. Schalm's Veterinary Hematology. 5ed. Philadelphia: Lippincolt Willians \& Wilkins, 2000, cap. 17, p.1100-1106.

NAOUM, P.C. Proteínas plasmáticas. In: Eletroforese, Técnicas e Diagnóstico. São Paulo: Santos, p.15-42, 1990.

OGILVIE, G.K.; WALTERS, L.M.; GREELEY, S.G. et al. Concentrations of alpha 1-acid glycoprotein in dogs with malignant neoplasia. J. Am. Vet. Assoc., v.203, p.1155-1146, 1993.

PINTO, F.C.H. Avaliação do crescimento do Tumor de Ehrlich em camundongos com alergia alimentar. 2003. 91p. Tese (Doutorado) - Escola de Medicina da UFMG, Belo Horizonte, MG.

PLOTON, D.; MENAGER, M; JEANNESSON, P. Improvement in the staining and the visualization of argyrophlic proteins of nucleolar organizer regions at the optical level. Histochem J., v.18, p5-14, 1986

ROMÃO-CORREA R.F., MARIA, D.A; SOMA, M. et al. Nucleolar organizer region staining patterns in paraffinembedded tissue cells from skin cancers. J. Cutaneous Pathol., v.32, p.323-328, 2005.

SAMPAIO, I.B.M. Estatística aplicada à experimentação animal. 1.ed. Belo Horizonte: Fundação de Ensino e Pesquisa em Medicina Veterinária e Zootecnia, 1998, 221p.
SEGURA, J.A.; BARBERO, L.G.; MÁRQUEZ, J. Early tumor effect on splenic Th lymphocytes in mice. FEBS Lett., v.414, p.1-6, 1997.

SEGURA, J.A.; BARBERO, L.G.; MÁRQUEZ, J. Ehrlich ascities tumour unbalances splenic cell populations and reduces responsiveness of $\mathrm{T}$ cell to Staphylococcus aureus enterotoxin B stimulation. Immunol. Lett., v.74, p.111-115, 2000

SENGER, D.R.; GALLI, S.J.; DVORAK, A.M. et al. Tumor cells secrete a vascular permeability factor that promotes accumulation of ascitic fluid. Science, v.219, p.983-985, 1983

SEYBOLD, L.M.; GOLDSTON, R.T.; WILKES, R.D. The chemical pathology laboratory examination of bone marrow. Vet. Med. Small Anim. Sci., Edwardsville, v.75, p.1517-1521, 1980

SILVA, A. E. Efeito do hipotireoidismo no tumor de Ehrlich na deficiência ou suficiência dos esteróides sexuais femininos. 2003. 85p. Dissertação (Mestrado) - Escola de Veterinária da UFMG, Belo Horizonte, MG.

SILVA, A.E.; SERAKIDES R.; FERREIRA, E. et al. Efeito do hipotiroidismo no tumor de Ehrlich sólido em camundongos fêmeas castradas e não castradas. Arq. Bras. Endocrinol. Metab., v.48, p.867-874, 2004.

SILVA, A.E.; SANTOS, F.G.A.; CASSALI, G.D. Marcadores de proliferação celular na avaliação do crescimento do tumor sólido e ascítico de Ehrlich. Arq. Bras. Méd. Zootec., v.58, p.658-661, 2006.

SOUZA-FAGUNDES, E.M.; GAZZINELLI, G.; PARREIRA, G.G. et al. In vitro activity of labdane diterpeno from Alomya myriadenia (Asteraceae): immunosuppression via induction of apoptosis in monocytes. Internat. Immunopharm. v.3, p.383-392, 2003a.

SOUZA-FAGUNDES, E.M.; BRUMATTI, G.; MARTINSFILHO, O.A. et al. Myriadenolide, a labdane diterpene isolated from Alomia myriadenia (Asteraceae) induces depolarization of mitochondrial membranes and apoptosis associated with activation of caspases-8, -9 , and -3 in Jurkat and THP-1 cells. Exp. Cell Res., v.290, p.420-426, 2003b.

VERÇOSA JÚNIOR, D. Avaliação do efeito da administração oral do Agaricus blazei Murrill no desenvolvimento do Tumor de Ehrlich sólido em camundongos. 2005. 67p. Dissertação (Mestrado) - Escola de Veterinária da UFMG, Belo Horizonte, MG.

WOOD, P.A.; HRUSHEDSKY W.J.; KLEVECZ R. Distinct circadian time structures characterize myeloid and erythroid progenitor and multipotential cell clonogenicity as well as narrow precursor proliferation dynamics. Exp Hematol. v.26, p.523-33, 1998 .

ZANI, C.; ALVES, T.M.A.; QUEIROZ, R. et al. A cytotoxic diterpene from Alomia myriadenia. Phytochemistry; v.53, p.877-80, 2000 . 